\title{
Inclusive Educational Technology
}

\author{
Ileana Hamburg \\ Institut Arbeit und Technik, WH Gelsenkirchen, Munscheidstr. 14, \\ D-45886 Gelsenkirchen, Germany \\ Sascha Bucksch \\ Institut Arbeit und Technik, WH Gelsenkirchen, Munscheidstr. 14, \\ D-45886 Gelsenkirchen, Germany
}

\begin{abstract}
Educational technology is a collection of research approaches to improve education aiming at effective use of technological tools to facilitate learning processes. There is little literature about inclusive educational technology. In this paper we present first a literature research about inclu-sive educational technology fostering inclusive education and improving the quality of life by increasing participation and reducing social exclusion. Organisational factors which assure an in-clusive education like competent teachers/trainers for the new roles and adequate educational technology curriculum are also presented in the paper. Inclusive educational technologies have been researched and applied by the authors also within some European projects. Within two of the projects ICT based platforms are in the development based on the research results.
\end{abstract}

Keywords: Educational technology, learning theories, inclusive education, inclusive ICT, learners with disa-bilities

\section{INTRODUCTION}

Educational technology is a complex field and there exist many definitions of it. We consid-er it as a collection of research approaches to improve education aiming at effective use of technological tools to facilitate learning processes.

Some learning theories are considered in educational technology approaches. The first one is behaviourism (developed in the 20th century) primarily concerned with observable behaviour, as opposed to internal events like thinking and emotion (Skinner, 1954).

Cognitivism concept involves how we think and gain knowledge examining learning, memory, problem solving skills, and intelligence. Cognitive researchers try to understand how problem solving changes throughout childhood, how cultural differences affect the way we view our own academic achievements, language development (deJong, 2010).

Constructivist learning is based on the use of students' prior knowledge and experiences to formulate new, related, and/or adaptive concepts in learning (Termos, 2012). The role of the teacher becomes that of a facilitator, providing guidance so that learners can construct new own knowledge. 
Social learning (Bandura, 1977) consider learning as a cognitive process that takes place in a social context and can occur purely through observation or direct instruction. It expands on traditional behavioural theories.

Some advantages to support learning through technology are open and flexible access to course materials, better interactions between students, teachers/trainers and student motivation, taking into consideration different learning styles by personalised learning environments.

Information and communication technologies (ICTs) should be used in all sectors of educa-tion and training, because technology skills are essential for global citizenship (European Agency, 2014). ICTs can be particularly efficient for learners with special needs who are vulnerable to the digital divide and to exclusion from some educational opportunities.

In this paper we refer to support particularly learners with disabilities but the measures and principles to support learners with disabilities are of benefit for other learners vulnerable to exclusion in any sector or education phase.

In our approach we speak about „inclusive educational technology” that foster inclusive education improving the quality of life by increasing participation and reducing social exclusion.

Inclusive education is a process of strengthening the capacity of the education system to reach out to all learners. As an overall principle, it should guide all education policies and practices, starting from the fact that education is a basic human right and the foundation for a more just and equal society" (European Agency, 2014). Inclusive education is in many Eu-ropean countries at the beginning. In Germany 80 percent of learners with special needs are in special schools, only about 20 percent attend a regular school. Sure the special educational schools are one way for development of learners with special needs but almost three quarters of all students at special schools do not achieve a secondary school qualification (UNESCO, 2008). Suitable ICT to support inclusive education are missing.

In this paper we present existing literature results of inclusive ICT (see part 2) as facilitators of inclusive education, promoting communication and learning and breaking down barriers that determine under-achievement and educational exclusion (Becta, 2007).

Inclusive educational technology research address not only increasing of efficiency of cur-rent ICT practices but also issues of learning, teaching and social organisation. So additional to inclusive ICT other organisational factors are important to assure an inclusive education like competent teachers/trainers for the new roles and adequate educational technology curriculum which are also presented in this paper. The topic of inclusive educational technolo-gies is researched by the authors also within some European projects. Within two of the pro-jects ICT based platforms are in the development based on the research results.

\section{Inclusive Educational Technology}

\section{LITERATURE RESEARCH}

Increasing inclusive education demands require significant changes in all education settings; so mainstream schools have to adapt to diverse groups of students having different needs (O`Gorman 2005; Istenic Starcic, 2009). Learning methods have to be adapted within a di-verse population; technologies which support this aspect have to be integrated. ICT play an important role in creating efficient, accessible and adaptable learning environments particu- 
larly in inclusive classrooms but most existing hardware and software do not take into consideration different competences/capabilities particularly of people with special needs (Wong et al, 2009). Inclusive ICTs supporting flexible personalised learning approaches and incorporating support for self-accommodation which could be used by learners with different needs are missing.

Some inclusive ICT which could be used in inclusive education are (European Agency, 2014):

- Mainstream technologies including computers, web browsers, word processors, whiteboards and mobile phones that contain in-built accessibility features to provide equally ef-fective access for learners with and without disabilities;

- Assistive Technologies including medical aids and also learning aids such as screen readers, alternative keyboards, augmentative and alternative communication devices and other specialised applications of technology used by individual learners with specific limi-tations in gaining access to ICTs;

- Compatibility between assistive technology products and mainstream technologies;

- Accessible media and formats;

- Accessible digital learning content and platforms based on learning management systems (LMS) and software.

As an important inclusive ICT tool „The Internet has acted as a platform for collaboration for all types of organisations. It has allowed for all citizens including people with disabilities, to engage more actively in social life. The Internet in itself could be considered as an assistive technology, allowing voices to be heard that traditionally could not be" said AnrietteEsterhuysen, Executive Director, and APC.

Social media services supporting social interactions in learning communities, cooperation and communication promote the development of social communication skills and feeding knowledge to one another, which learners have to possess as adults, through social learning.

Providing inclusive ICT for students with disabilities involves removing barriers i.e. physical barriers, content and materials which are not accessible, cognitive barriers for some learners with intellectual disabilities or specific learning problems, content barriers that may occur when the operating language of a device or software is not the same as a learner's mother tongue, didactical barriers where learning is inflexible and teachers lack of the skills to facilitate inclusive education, financial barriers relating to the costs of devices and software.

The use of ICT in inclusive educational technology requires many sectors of expertise and activities (European Agency, 2014) like stakeholders input and views, training of education professionals and of ICT developers.

Some principles to be taken into consideration in inclusive educational technology are:

- an active involvement of learners with disabilities, their families/representatives in the de-velopment,

- implementation and evaluation of services which facilitates learners access to an inclusive educational technology and other inclusive opportunities,

- The provision of inclusive ICT in education of people with disabilities to be aligned with the goals of inclusive education and should be available for formal, informal, blended, so-cial and other forms of learning. 
- The implementation of an inclusive ICT in inclusive education should take a systemic ap-proach.

\section{Organisational Problems In Inclusive Educational \\ Technology}

Teacher education has been recognized as a future development area also at the 48th International Conference on Education, Inclusive Education: The Way of the Future (UNESCO, 2008).

In order to support inclusive education teacher education should be promoted i.e. through (Donnelly and Watkins, 2011):

- Integrating special and general education of teachers

- Learning to develop innovative teaching way to promote active student learning and adaptations to meet students with special needs

- Learning to develop curriculum strategies which include broad common goals, flexible structures, and different assessments.

Despite guidelines and plans for teacher training for inclusive education, many of them re-port that they are unprepared to work effectively with the students with special needs. Lack of training, planning time and resources to research suitable approaches are some causes.

The education of the teaching staff should promote the inclusive educational technology that means the use of inclusive ICT which play a decisive role in the learning process. It requires a change in the work of teachers who have to consider that the learning for the students is different from that they know until now. The teachers have to achieve digital competences for using blended methods i.e. to combine face to face sessions with virtual environments, to use digital content which has to be defined according to criteria which assure accessibility for all students. The review of existing literature shows a lack of attention to the use of inclusive ICT in education (Istenic Starcic, 2010).

Referring the inclusive educational technology curriculum for students to become teachers it has to be changed to incorporate topics of inclusive ICT use within inclusive education. Students have to understand the potential of inclusive ICT in inclusive classrooms and for accommodation of students with special needs in the integrated classes. Learning environments have to be used to foster cooperative learning of students.

In the schools and higher institutions learning communities for students and environments have to be used to foster cooperation and exchanged of ideas between teachers and also with parents of learners with special needs in order to improve the efficiency of inclusive education.

\section{RESEARCH APPROACH}

Inclusive educational technologies have been researched within European projects. The methods were literature research, questionnaires, and focus group discussions, dynamic session with the participation of learners with disabilities, trainers/teachers and in some cases parents. Some developments have been done and tested with learners with disabilities. In the following we present the activities in this context done within some projects worked by the authors in the last two year and in present. 
In the frame of the European learning partnership TRAINDIPICTS (www.traindipicts.eu) the project partners collected best practices for the use of ICT to best address the problems appearing in the integration of people with disabilities education. The project paid particularly attention on best practices for motoric-, visual- and hearing impaired people in order to integrate them in ordinary education and working places with the help of ICT.

\section{ICT Support for Motoric Impaired People}

Motor impairment is the partial or total loss of function of a body part, usually a limb or limbs. This may result in muscle weakness, poor stamina, and lack of muscle control or total paralysis. Motor impairment is often evident in neurological conditions such as cerebral palsy, Parkinson's disease, stroke and multiple sclerosis.

For people with motor impairments who can handle with computers in principle, but with limitations, the use of special keyboards adjusted to their needs (large field, small field, mini field) will often be enough to use a computer. Those who are not able to use mouse and keyboard can use the computer with the help of sensors and special software to control it by knees, elbows, head motions, mouth or even through eye tracking.

People, who are not able to talk, depend on alternative communication means to express their needs. Modern computer with a voice synthesizer offer a number of input devices and alternates the voice of the person. It works on basis of pictures and written texts. There also exist some apps with speak synthesis for modern tablet computers, which can be used by eye control or touch screen.

\section{ICT Support for Hearing Impaired People}

All levels of qualification are open for young people with hearing loss in principle. Almost all children who have received a cochlear implant, a prosthetic device that enables them to perceive sound and understand speech, at an early age attend kindergarten and go to an ordi-nary school. But they need much more support; the levels of assistance they obtain are no-where near adequate. Other approaches to help people with loss of hearing are systems to translate spoken or written sentences into sign language. A computer records the spoken or written sentences and shows the translation on the computer screen. Examples are the Thetos by the Silesian University of Technology in Poland or CONSIGNOS from the company AETecnoAmeco.

\section{ICT Support for Visual Impaired People}

Blind people rely on tools to use a computer. They can make use of tactile sense and on hearing to operate on a computer. A best practice, conducted by the Dresden University of Technology, is to make study material accessible by blind and partially sighted people i.e. documents available on the World Wide Web. The university developed a transformation service for HTML documents into English, French and German braille following the guidelines of the International Committee for Accessible Document Design ICADD. The project „Audio-tactile CBT for blind masseurs and physiotherapists" dealt with gap in the training of blind people as masseurs and physiotherapists in subjects like anatomy, electrotherapy, because they do not have complete access to the textbooks in these subjects and they cannot use modern multimedia software for education and training. The general in of the project was the development and use of audio-tactile information systems for the blind. Speaking maps, ground plans, network diagrams, plans of museums and exhibitions and so on are available. The user puts a tactile overlay onto a touch pad, touches it with his fingers and gets spoken information controlled by a PC. Within the project an ATT system was developed, which involved these technologies and successfully fulfilled every requirement to train blind masseurs. 
The main objective of the ongoing Erasmus + project IDIPOWER (Empowering disabled people through collaborative learning) is a reorientation of the roles of ICT based learning support services and their providers/developers so that to help people with disabilities to in-tegrate in education and life and be more independent. By using collaborative learning with-in the support systems, people with disabilities should become active participants in planning of their learning processes and could obtain the help which best meets their education and life needs and goals.

Within the project existing support systems of the project partner countries (coming from five European countries) - also for learning - have been discussed and compared. Questionnaire have been sent to people with disabilities, trainers and parents and working dynamic sessions have been organised in the partner countries to discuss improving in the existing supporting systems and the learning technologies used. It has been discussed, together with parents, the possibilities to send their children with disabilities in classes together with people without disabilities (inclusive classes). Training modules for three levels of users are in the development based on the researched inclusive educational technologies. The training helps also teachers/trainers who worked supplementary with people with disabilities in inclusive classes.

An online platform of IDIPOWER has been developed by using TikiWiki to support learners in collaborative work and to enable people with disabilities access to learning material. They can learn by the use of blended learning methods and discussion forums for trainers and fam-ilies. A social network with user profiles provides the learner the possibility of creating a learning community and use social learning (Figure 1).

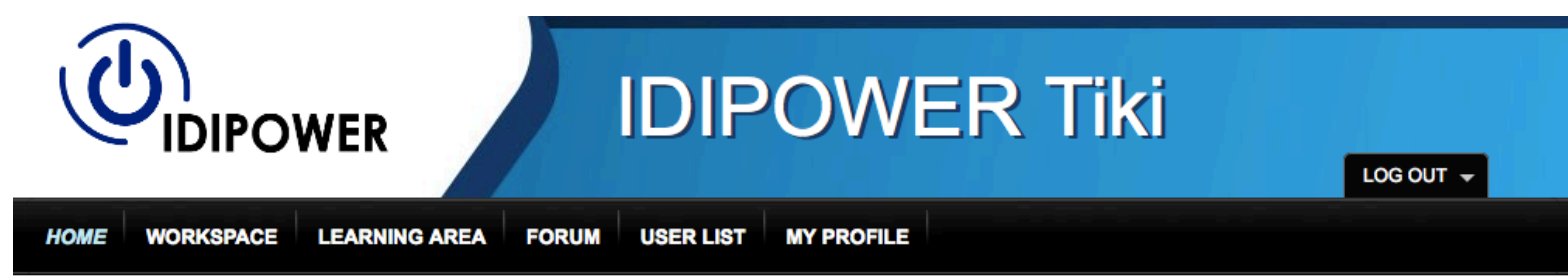

\section{Description of the menu bar}

Switch Language

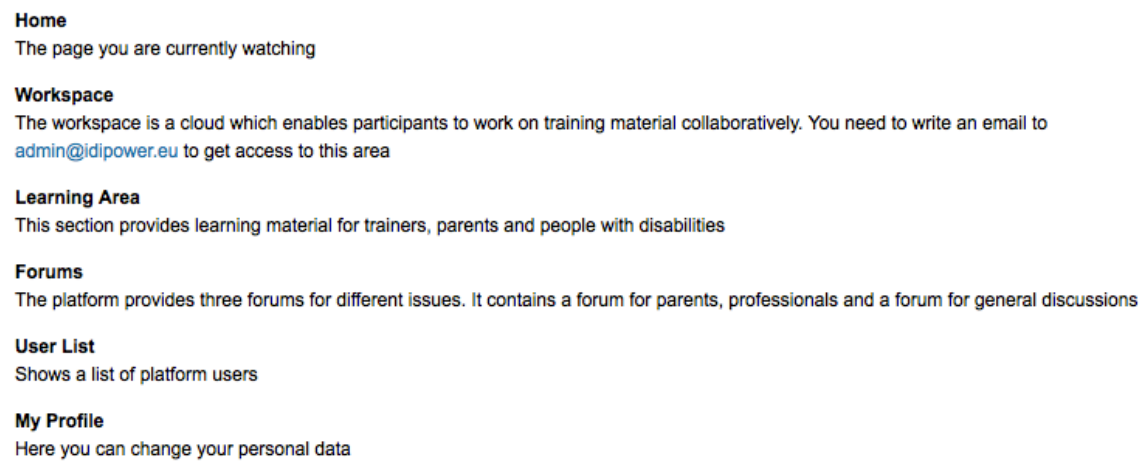

Figure 1: IDIPOWER Platform - http://tiki.idipower.eu 
The ongoing European Erasmus+ project idICT - Development of a training program for improving the Quality of Life of Persons with Intellectual Disabilities through the use of ICT solutions - aims at the use of inclusive educational technologies to improve the education and independent living particularly of this group. Existing ICT and possibilities to be used in inclusive education will be identified and asses. Training programs to use such inclusive ICT for people with intellectual disabilities and trainers will be developed and tested in five Eu-ropean partner countries. It is intended to promote inclusive education for people with intel-lectual disabilities.

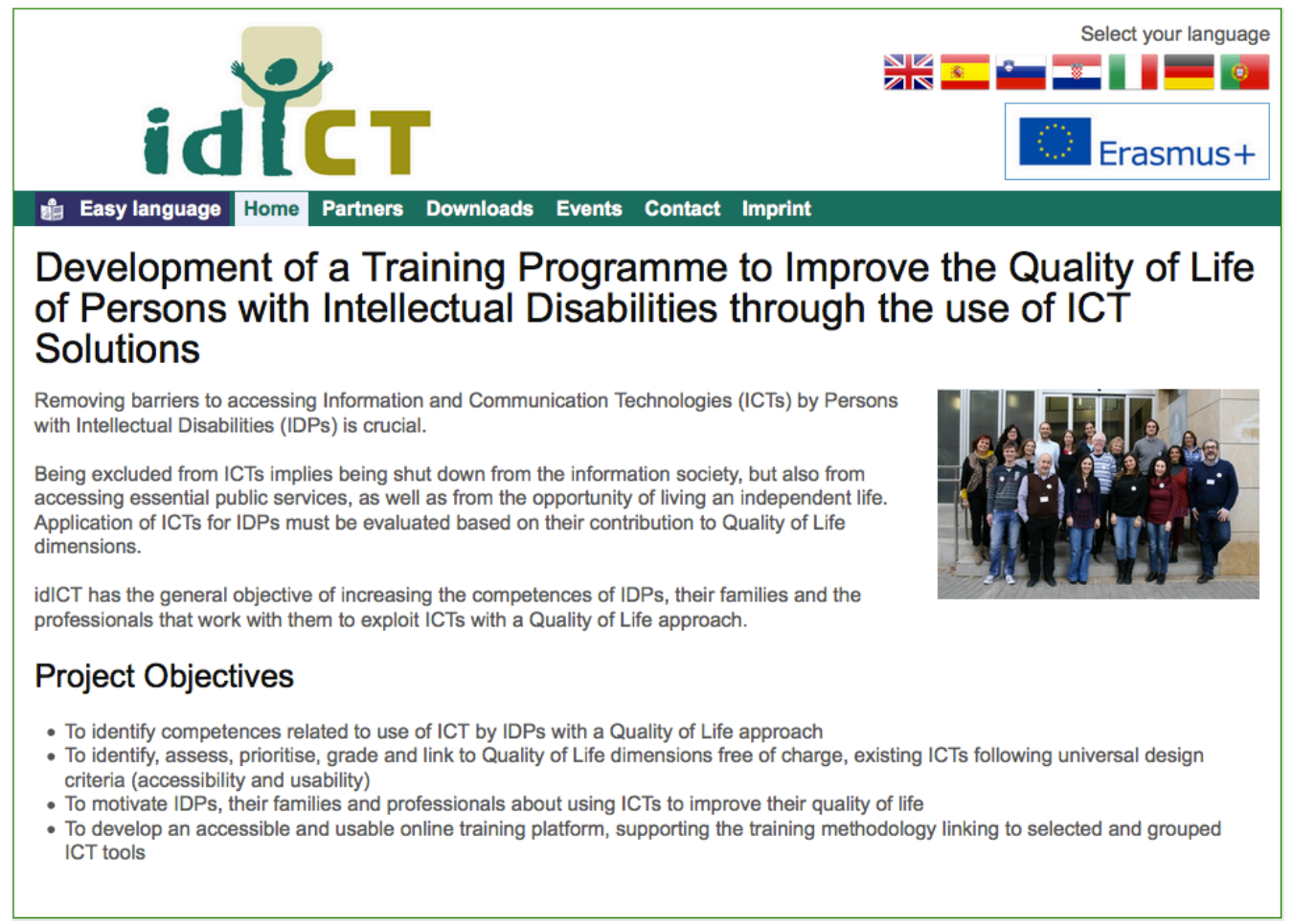

Figure 2: idICT website - www.id-ict.eu

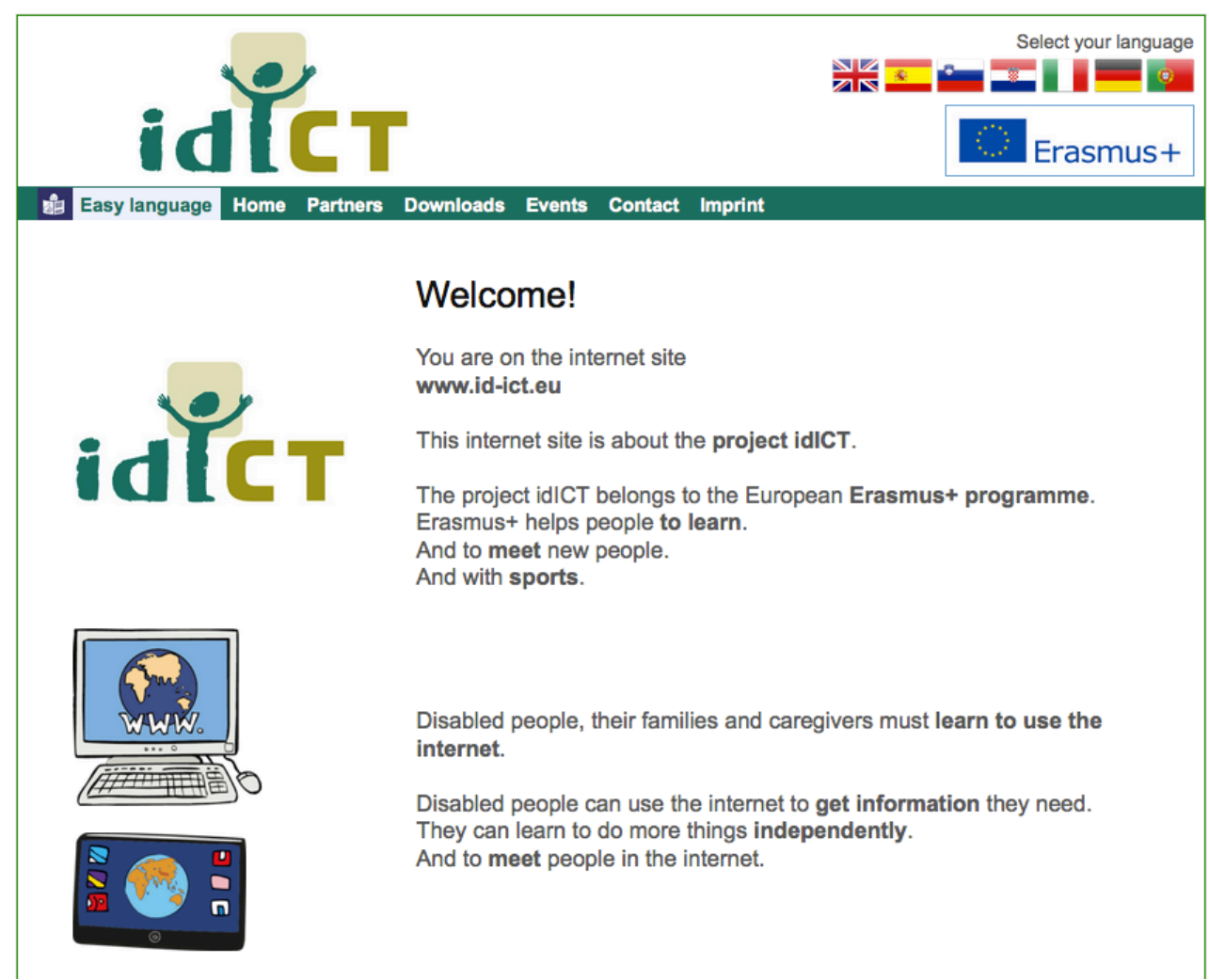

Figure 3: idICT website in easy to read language 
The web-site and the platform which are in the development are based on easy to read language (Figure 3).

\section{RESULTS AND CONCLUSIONS}

It is known that ICT competences both for people with disabilities as well as for their teachers/trainers are enabler for an active participation in a knowledge based society.

Ensuring inclusive ICT for persons with disabilities and expanding access to these technologies should become a key element in improving inclusive educational technology. So ICT must be an integral part of an inclusive education. Results of our projects show that a vision of an inclusive development and a society in which persons with disabilities are participants and beneficiaries of development brings advantages at all educational levels, help people with disabilities to be competitive in the labor market, to participate in public life and to live independently.

Two research questions will be considered in the future work of the authors: how could be maximized the role or advanced ICT in inclusive education and what are the social and hu-man consequences of adopting inclusive ICT.

\section{ACKNOWLEDGMENTS}

This paper described work within the on-going European Erasmus+ projects IDIPOWER and idICT.

\section{References}

Baglieri, S., Shapiro, A., 2012.Disability Studies and the Inclusive Classroom. New York, NY: Routledge

Bandura A.J., 1977. Social learning theory. New York: General Learning Press

Becta, 2007.Inclusive learning: an essential guide. Retrieved from http://bee-

it.co.uk/Guidance\%20Docs/Becta\%20Files/Publications/29.\%20Inclusive\%20learning\%20An\%20essential\%20 guide.pdf

David, A., Hamburg, I. 2013. Integrating vulnerable and marginalized groups into vocational education and training through innovative solutions. In Problems of education in the 21 st century, 56, pp. 42-58

DeJong, T., 2010. Cognitive Load Theory, Educational Research, and Instructional Design: Some Food for Thought. Instructional Science: An International Journal of the Learning Sciences, p. 38

Donelly, V., Watkins, A., 2011.Teacher education for inclusion in Europe. Prospects, 41, 3, pp. 341-53

European Agency, 2014.Model policy for inclusive ICTs in education for persons with disabilities. Retrieved from https://www.european-agency.org/

Sites/default/files/UNESCO-G3ict\%20Model

\%20Policy\%20on\%20Inclusive\%20ICTs\%20for\%20Education\%204-2014.pdf

Hamburg, I., Bucksch, S., 2015.ICT-based approaches to support learners with disabilities. InJournal of educational policy and entrepreneurial research (JEPER) 2, no. 6, pp. 1-12

IstenicStarcic, A., 2009. Educational technology syllabus. In UP PEF higher education, pp. 12-15 Koper

O'Gorman, E., 2005. Setting Standards for Teacher Education in Special Educational Needs in Ireland.In 30th Annual Conference ATEE. Amsterdam, October 2005, pp. 377-381

Porter, L., Smith, D. (Eds.), 2011. Exploring inclusive educational practices through professional inquiry. Boston, MA: Sense Publishers

Richey, R.C., 2008. Reflections on the 2008 AECT Definitions of the Field. InTechTrends 52 (1), pp. 24-25 
Skinner, B.F., 1954. The science of learning and the art of teaching.Harvard Educational Review 24, pp. 86-97

Termos, M., 2012. Does the Classroom Performance System (CPS) Increase Students' Chances for Getting a Good Grade in College Core Courses and Increase Retention? InInternational Journal of Technologies in Learning 19 (1), pp. 45-56

TiKiWikicms groupware http://www.tikiwiki.org

UNESCO, 2008.Inclusive education in Germany. Retrieved from https://www.unesco.de/en/bildung/inklusivebildung/inklusive-bildung-deutschland.html

Wong A.W.K., Chan, C.C.H., Li-Tsang, C.W.P., Lam, C.S., 2009. Competences of people with intellectual dis-abilities in using human-computer interface. InResearch in Development disabilities, 30, pp. 107-123 